\title{
Effect of Fetal Hemoglobin on the Determination of Neonatal Cerebral Oxygenation by Near-Infrared Spectroscopy
}

\author{
Y. A. B. D. WICKRAMASINGHE, K. S. PALMER, R. HOUSTON, S. A. SPENCER, P. ROLFE, \\ M. S. THORNILEY, B. OESEBURG, AND W. COLIER \\ Department of Biomedical Engineering and Medical Physics [Y.A.B.D.W., R.H., P.R., M.S.T.] and Department \\ of Paediatrics, University of Keele, Hospital Centre, Stoke-on-Trent, United Kingdom [K.S.P., S.A.S.]; and \\ Department of Physiology, University of Nijmegen, The Netherlands [B.O., W.C.]
}

\begin{abstract}
Near-infrared spectroscopy has been applied to the study of cerebral oxygenation and hemodynamics in the newborn. Fetal $\mathrm{Hb}$ is present in high concentrations in these infants. Because spectral absorption curves in the near-infrared range for fetal $\mathrm{Hb}$ are not identical to those for adult $\mathrm{Hb}$, there is a potential for the measurements to be affected. This possibility has not previously been investigated. A quantitative analysis of cerebral oxygenation was undertaken in six newborn infants. The analysis used near-infrared spectroscopy multiplier coefficients derived from the absorption coefficients of both fetal and adult deoxygenated and oxygenated $\mathrm{Hb}$. The results of both analyses were compared. It was concluded that the error in near-infrared spectroscopy analysis of neonatal cerebral oxygenation arising from the use of absorption coefficients derived from adult $\mathrm{Hb}$ is inconsequential, even in the presence of high concentrations of fetal Hb. (Pediatr Res 34: 15-17, 1993)
\end{abstract}

\section{Abbreviations}

NIRS, near-infrared spectroscopy

NIR, near infrared

[Hb], cerebral deoxyhemoglobin concentration

$\left[\mathrm{HbO}_{2}\right.$, cerebral oxyhemoglobin concentration

$\mathrm{SaO}_{2}$, arterial oxygen saturation

$\mathrm{CBF}$, cerebral blood flow

CBV, cerebral blood volume

The technique of NIRS has been used in the investigation of cerebral oxygenation and hemodynamics in the newborn (1-3). The preliminary investigations were based on changes in [ $\mathrm{Hb}]$, $\left[\mathrm{HbO}_{2}\right]$, total cerebral $\mathrm{Hb}$ concentrations and cytochrome $a a_{3}$. These data were presented as relative changes due to the uncertainty of the estimation of optical path length. Scattering of light by tissues causes the optical path length to be much greater than the physical path length. Time-of-flight measurements through biologic tissue (4) now permit quantification of these changes as well as provide absolute values for $\operatorname{CBF}$ and $\operatorname{CBV}(5,6)$. Such quantification is also dependent on accurate absorption coefficients for $\mathrm{Hb}$.

Seventy-five percent or more of the $\mathrm{Hb}$ in the blood of newborn infants is fetal $\mathrm{Hb}$, but this falls to around $5 \%$ by the age

Received June 10, 1992; accepted December 1, 1992.

Correspondence: Dr. S. A. Spencer, Department of Paediatrics, Hospital Centre, Stoke-on-Trent, ST4 6SD, UK.

Supported by the North Staffordshire Health Authority, Science and Engineering Research Council and Action Research and Ciba-Corning Diagnostics Ltd-UK. of $6 \mathrm{mo}(7)$. The decline is much more rapid in premature infants who receive transfusions with adult blood. Spectrophotometric multicomponent analysis of $\mathrm{Hb}$ derivatives for fetal blood $(8,9)$ and the effects of fetal $\mathrm{Hb}$ on the analysis of $\mathrm{Hb}$ pigments by multiwavelength oximetry have been studied (10). Although the spectral absorption curves for adult and fetal $\mathrm{Hb}$ are of similar shape over the relevant spectral range of 450 to $100 \mathrm{~nm}$, the small differences between them are of sufficient importance to suggest that they should be taken into account in multicomponent analysis of $\mathrm{Hb}$ derivatives (11). The purpose of this study was to determine whether it is necessary to modify the coefficients used in NIRS calculations when fetal $\mathrm{Hb}$ is present.

\section{MATERIALS AND METHODS}

Theory. NIRS monitoring of cerebral oxygenation uses light in the range 775 to $990 \mathrm{~nm}(12,13)$. The method requires knowledge of the absorption coefficients of $\mathrm{HbO}_{2}, \mathrm{Hb}$, and cytochrome $a a_{3}$. Changes in the concentrations of these chromophores can be expressed in terms of changes in the absorbance measured at 775,845 , and $904 \mathrm{~nm}$ (14). For example, the change in the $[\mathrm{Hb}]$ can be expressed as:

$$
\Delta[\mathrm{Hb}]=\left(\mathrm{P} \Delta \mathrm{A}_{775}+\mathrm{Q} \Delta \mathrm{A}_{845}+\mathrm{R} \Delta \mathrm{A}_{904}\right) / \mathrm{nd}
$$

where $\Delta$ refers to changes. The terms $\mathrm{P}, \mathrm{Q}$, and $\mathrm{R}$ are obtained by matrix inversion from the absorption coefficients of $\mathrm{Hb}$, $\mathrm{HbO}_{2}$, and cytochrome $a a_{3}$. The direct spacing between the transmitting and receiving optical fiber probes placed on the neonatal head is taken as d. The scattering of NIR light leads to an increase in optical path length in the tissue, and this path length multiplication factor ( $n$ ) has been found to be 4.3 (4). Thus, the change can be expressed in $\mu \mathrm{mol} / \mathrm{L}$.

The results of the spectroscopic determination of absorption coefficients of fetal $\mathrm{Hb}$ and adult $\mathrm{Hb}$, as measured by Zijlstra et $a l(11)$, and our coefficients for cytochrome $a a_{3}$ were used. Table 1 gives these absorption coefficients for the wavelengths used. Using these, we arrived at two sets (Table 2) of "NIR multiplier

Table 1. Absorption coefficients of adult and fetal $\mathrm{Hb}$ and cytochrome $a a_{3}{ }^{*}$

\begin{tabular}{cccc}
\hline & \multicolumn{3}{c}{ Wavelength } \\
\cline { 2 - 4 } Chromophore & $775 \mathrm{~nm}$ & $845 \mathrm{~nm}$ & $904 \mathrm{~nm}$ \\
\hline $\mathrm{HbO}_{2} \mathrm{a}$ & 0.68 & 1.00 & 1.20 \\
$\mathrm{Hba}^{\mathrm{HbO}} \mathrm{f}^{\mathrm{f}}$ & 1.16 & 0.76 & 0.84 \\
$\mathrm{Hbf}$ & 0.64 & 0.96 & 1.12 \\
$\mathrm{Cyt}$ & 1.16 & 0.72 & 0.80 \\
& 1.75 & 2.83 & 1.27 \\
\hline
\end{tabular}

* a, adult; f, fetal; cyt, cytochrome $a a_{3}$. 
Table 2. Two sets of NIR multiplier coefficients: NIRA obtained using absorption coefficients of adult Hb and NIRF using those of fetal $\mathrm{Hb}$

\begin{tabular}{lrrrrrrr}
\hline & \multicolumn{3}{c}{ NIRA } & & \multicolumn{3}{c}{ NIRF } \\
\cline { 2 - 4 } \cline { 5 - 7 } Concentration & $775 \mathrm{~nm}$ & $845 \mathrm{~nm}$ & $904 \mathrm{~nm}$ & & $775 \mathrm{~nm}$ & $845 \mathrm{~nm}$ & $904 \mathrm{~nm}$ \\
\hline$\left[\mathrm{HbO}_{2}\right]$ & -1.023 & -0.0028 & 1.415 & & -1.014 & -0.055 & 1.52 \\
{$[\mathrm{Hb}]$} & 1.541 & -0.896 & -0.126 & & 1.465 & -0.862 & -0.098 \\
{$[\mathrm{Hb} \text { tot] }]^{*}$} & 0.518 & -0.899 & 1.289 & & 0.451 & -0.917 & 1.422 \\
\hline
\end{tabular}

* [ $\mathrm{Hb}$ tot], total cerebral Hb concentration.

coefficients": NIRF, obtained using fetal $\mathrm{Hb}$ absorption coefficients; and NIRA, obtained using adult $\mathrm{Hb}$ absorption coefficients.

Subjects. Six infants were studied. They were all receiving additional oxygen therapy for respiratory distress syndrome or transient tachypnea of the newborn. To ensure high levels of fetal $\mathrm{Hb}$, the studies were all performed during the lst wk of life and before any blood transfusion. In some of these infants, the percentage of fetal $\mathrm{Hb}$ was measured from preoxygenated arterial or venous blood samples, using an OSM3 hemoximeter (Radiometer, Copenhagen, Denmark). To determine the effects of decreasing levels of fetal $\mathrm{Hb}$, three studies were performed in one baby over a period of $48 \mathrm{~d}$. During this time, the baby received four transfusions with adult blood, and the resulting change in fetal $\mathrm{Hb}$ was measured.

Procedure. The NIRS probes were placed on the infant's head and held in place a measured distance apart using double-sided adhesive rings and elastic webbing.

In all studies, the direct spacing between the optical probes was more than $4 \mathrm{~cm}$. Each study consisted of an induced fall in $\mathrm{SaO}_{2}$ by 10 to $15 \%$ from resting values of 95 to $98 \%$ by altering the inspired oxygen for a period of $5 \mathrm{~min}$, then returning it to the initial value. This allows changes in the oxygenated $\mathrm{Hb}$ and $\mathrm{Hb}$ to be calculated during the fall in $\mathrm{SaO}_{2} . \mathrm{SaO}_{2}$ and heart rate were monitored using an N200 pulse oximeter (Nellcor-Inc., Hayward, CA) with the sensor attached to the foot.

This study was approved by the local ethical committee, and informed consent was obtained from the parents of the subjects.

\section{RESULTS}

The results of performing the calculation using both the adult and fetal $\mathrm{Hb}$ absorption coefficients were investigated for $\left[\mathrm{HbO}_{2}\right]$ and $[\mathrm{Hb}]$. Here, $\left[\mathrm{HbO}_{2}\right] \mathrm{A}$ and $[\mathrm{Hb}] \mathrm{A}$ refer to changes in the concentration of oxy- and deoxyhemoglobin calculated using NIRA multiplier coefficients, whereas $\left[\mathrm{HbO}_{2}\right] \mathrm{F}$ and $[\mathrm{Hb}] \mathrm{F}$ refer to values obtained using NIRF multiplier coefficients (Table 2). The relationship between the results obtained using the different coefficients was tested for both $\left[\mathrm{HbO}_{2}\right]$ and $[\mathrm{Hb}]$, using linear regression analysis to examine the slope and intercept. For $\left[\mathrm{HbO}_{2}\right]$, the average values for slope and intercept were found to be $0.971 \pm 0.01$ and $0.003 \pm 0.0028$, respectively; $r$ was $0.998 \pm$ 0.0023 . For $[\mathrm{Hb}]$, the average values for the slope and intercept were $1.049 \pm 0.002$ and $0.002 \pm 0.0009$, respectively; average value for $r$ was $0.999 \pm 0.0007$. Figure 1 shows a scatter diagram with the line of identity for change in $\left[\mathrm{HbO}_{2}\right]$ during a desaturation study calculated using two different sets of NIR coefficients as given in Table 2 .

Table 3 gives the results of the analysis in which the same baby was studied using NIRS after a blood transfusion. There was not any significant difference between the calculated values under different percentages of fetal $\mathrm{Hb}$. The closeness to unity of the slope and to origin of the intercept for both $\left[\mathrm{HbO}_{2}\right]$ and $[\mathrm{Hb}]$ clearly shows that the error in NIRS analysis resulting from the use of adult $\mathrm{Hb}$ absorption coefficients in the presence of varying concentrations of fetal $\mathrm{Hb}$ is inconsequential.

The sensitivities of the NIR multiplier coefficients to the measured absorption coefficients were calculated by differentiating the equations derived by Cramer's Rule for matrix inversion

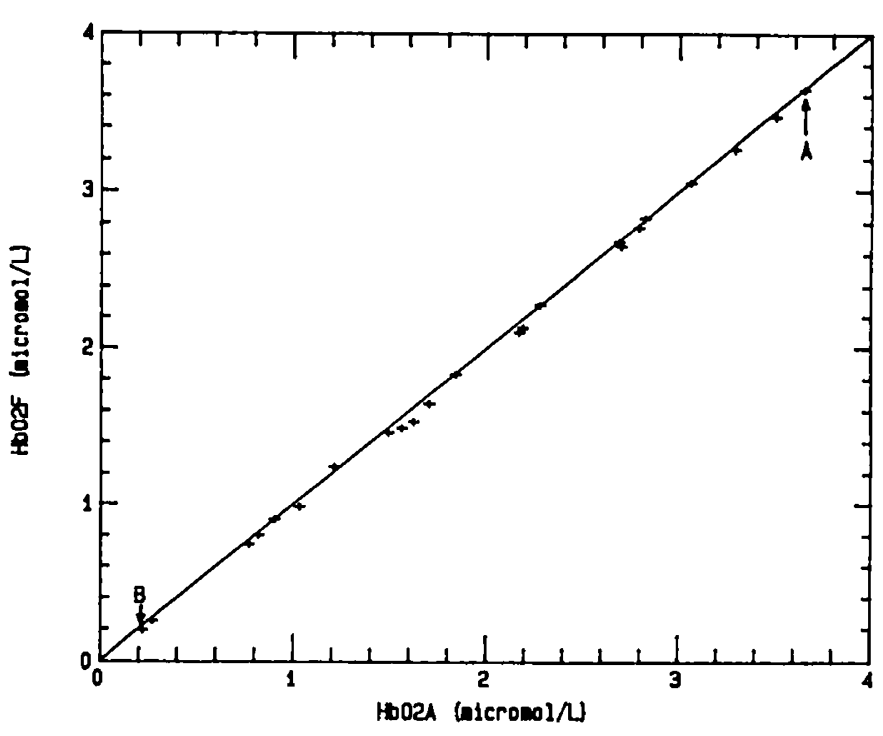

Fig. 1. Scatter diagram of data points, with line of identity for $\left[\mathrm{HbO}_{2}\right]$ calculated using adult (NIRA) and fetal (NIRF) NIR multiplier coefficients ( $H b O 2 A$ and $H b O 2 F$, respectively). The change was caused by a transient fall in $\mathrm{SaO}_{2}$. At $A$, the saturation was $93.8 \%$, falling to $85.7 \%$ at $B$.

Table 3. Same baby (birth weight $1080 \mathrm{~g}$; RDS) studied after blood transfusion, when the fetal $\mathrm{Hb}$ had fallen from $100 \%$ (d 6 ) to $23 \%(d 48)^{*}$

\begin{tabular}{lccccc}
\hline & Slope & SEM & Intercept & SEM & $r$ \\
\hline [ $\mathrm{HbO}_{2}$ ] A and [HbO & \\
Age 6 d $(100 \%) \dagger$ & & & & & \\
Age 7 d (75\%) & 0.960 & 0.014 & -0.0001 & 0.004 & 0.998 \\
Age 48 d (23\%) & 0.989 & 0.006 & 0.006 & 0.002 & 0.999 \\
[Hb]A and [Hb]F & & 0.004 & -0.003 & 0.001 & 0.999 \\
Age 6 d (100\%) & 1.052 & 0.003 & 0.003 & 0.0006 & 0.999 \\
Age 7 d (75\%) & 1.052 & 0.002 & -0.0008 & 0.0009 & 0.999 \\
Age 48 d (23\%) & 1.051 & 0.001 & 0.001 & 0.0005 & 0.999 \\
\hline
\end{tabular}

* Results show that adult $\mathrm{Hb}$ coefficients can be applied to infants irrespective of the levels of fetal $\mathrm{Hb}$ present without introducing a significant error. RDS, respiratory distress syndrome; $A$, adult; $F$, fetal.

$\dagger$ Number in parentheses indicates percentage of fetal $\mathrm{Hb}$.

(15). All sensitivities were $<3$. This means that for a given increment in any one absorption coefficient, no multiplier changes by more than three times that increment. This shows that the system of equations relating NIR absorbance changes to chromophore concentration changes is well conditioned. Thus, it has been demonstrated experimentally that the effects of small changes in absorption coefficients will be small.

\section{DISCUSSION}

Application of spectrophotometric multicomponent analysis to the determination of $\mathrm{Hb}$ derivatives in neonatal blood may theoretically lead to incorrect results due to the presence of fetal $\mathrm{Hb}$. This is because of the difference in absorption spectra of adult and fetal $\mathrm{Hb}$ derivatives. The magnitude of the error depends on the wavelength of light that is used for different monitoring techniques. The contribution of varying concentrations of fetal $\mathrm{Hb}$ on pulse oximeter readings has been studied and has been found not to influence the accuracy of the results (16). However, it cannot be assumed that this applies to NIRS because different wavelengths of light are used. The fact that in clinical investigations NIRS uses absorption coefficients obtained from adult $\mathrm{Hb}$ has raised the question of whether this could lead 
to errors when NIRS is applied to investigations in the neonate or fetus.

Clinical use of NIRS to monitor cerebral oxygen sufficiency, $\mathrm{CBF}$ and $\mathrm{CBV}$ in the neonate and fetus is increasing. Measurements of change in CBV have been compared with results obtained using jugular venous occlusion plethysmography (6) and measurements of $\mathrm{CBF}$ have been compared with results obtained by xenon clearance (17), thus providing a sound basis for further studies. If the presence of fetal $\mathrm{Hb}$ were to lead to errors in the quantified NIRS parameters when such studies are carried out, then account would have to be taken of this in the analysis. A series of coefficients would be necessary to allow for varying concentrations of fetal $\mathrm{Hb}$. The percentage of fetal $\mathrm{Hb}$ present in the subject would also need to be determined before the data could be analyzed, which would limit the application of NIRS in the neonatal field.

This study has clearly demonstrated that adult $\mathrm{Hb}$ coefficients can be applied to infants, irrespective of the level of fetal $\mathrm{Hb}$ present, without introducing a significant error. This is particularly important for serial measurements in infants during the early weeks of life.

Acknowledgment. The authors thank the parents who gave their consent to our studies.

\section{REFERENCES}

1. Brazy JE, Lewis DV, Mitnick MH, Jobsis Van der Vliet FF 1985 Noninvasive monitoring of cerebral oxygenation in preterm infants: preliminary observations. Pediatrics 75:217-225

2. Wyatt JS, Cope M, Delpy DT, Wray S, Reynolds EOR 1986 Quantitiation of cerebral oxygenation and haemodynamics in sick newborn infants by near infrared spectrophotometry. Lancet 2:1063-1066

3. Livera NL, Spencer SA, Thorniley MS, Wickramasinghe YABD, Rolfe P 1991 Effects of hypoxemia and bradycardia on neonatal cerebral haemodynamics. Arch Dis Child 66:376-380
4. Delpy DT, Cope M, van der Zee P, Arridge S, Wray S, Wyatt JS 1988 Estimation of optical path length through tissue from direct time of flight measurements. Phys Med Biol 33:1432-1442

5. Edwards AD, Wyatt JS, Richardson C, Potter A, Cope M, Delpy D, Reynolds EOR 1990 Effects of indomethacin on cerebral haemodynamics in very preterm infants. Lancet 335:1491-1495

6. Wickramasinghe YABD, Livera LN, Spencer SA, Rolfe P, Thorniley MS 1992 Plethysmographic validation of near infrared spectroscopic monitoring of cerebral blood volume. Arch Dis Child 67:407-411

7. Delivoria-Papadopoulos M, Roncerrie N, Oski F 1971 Postnatal changes in oxygen transport of term preterm and sick newborn infants: the role of 2,3diphosphoglycerate and adult hemoglobin. Pediatr Res 5:235-245

8. Zwart A, Buursma A, Oeseburg B, Zijlstra WG 1981 Determination of hemoglobin derivatives with the IL282 co-oximeter as compared with a manual spectrophotometric five wavelength method. Clin Chem 27:1903-1907

9. Huch R, Huch A, Tuchsmid P, Zijlstra WG, Zwart A 1983 Carboxyhemoglobin concentration in fetal cord blood. Pediatrics 71:461-462

10. Fogh-Anderson N, Siggaard-Andersen O, Lundsgaard FC, Wimberly PD 1987 Spectrophotometric determination of haemoglobin pigments in neonatal blood. Clin Chim Acta 166:291-296

11. Zijlstra WG, Buursma A, Meeuwsen-van der Roest WP 1991 Absorption coefficients of human fetal and adult oxyhemoglobin, de-oxyhemoglobin, carboxyhemoglobin and methemoglobin. Clin Chem 9:1633-1638

12. Rea PA, Crowe J, Wickramasinghe YABD, Rolfe P 1985 Noninvasive optical methods for the study of cerebral metabolism in the human newborn: a technique for the future? J Med Eng Technol 4:160-166

13. Martin MJ, Wickramasinghe YABD, Newson TP, Crowe J 1987 Fibre optics and optical sensors in medicine. Med Biol Eng Comput 25:597-604

14. Wickramasinghe YABD, Thorniley MS, Rolfe P, Livera NL, Spencer SA 1989 Development of algorithms for in vivo noninvasive monitoring in biological tissue using near infrared spectroscopy. Proceedings of the 5th Mediterranean Conference on Medical and Biological Engineering, Patras, Greece, pp 252253

15. Kreyszig E 1972 Advanced Engineering Mathematics. Wiley, New York, pp $679-681$

16. Ramanathan R, Durand M, Larrazabal C 1987 Pulse oximetry in very low birth weight infants with acute and chronic lung disease. Pediatrics 4:612617

17. Pryds O, Greisen G, Skov LL, Friis-Hansen B 1990 The effects of $\mathrm{PaCO}_{2}$ induced increase in cerebral blood volume and cerebral blood flow in mechanically ventilated, preterm infants. Comparison of near infrared spectroscopy and ${ }^{133}$ xenon clearance. Pediatr Res 27:445-449 